\title{
A STUDY OF EPIDEMIOLOGICAL PATTERN OF MULTIDRUG RESISTANT PULMONARY TUBERCULOSIS PATIENTS PRESENTING TO A TERTIARY CARE CENTRE IN CENTRAL INDIA
}

\author{
Sanjay Avashia'1, Deepak Bansal2, Salil Bhargava ${ }^{3}$, Ankit Tomar4, Satyadeo Choubey ${ }^{5}$ \\ ${ }^{1}$ Associate Professor, Department of Pulmonary Medicine, MGM Medical College, Indore. \\ ${ }^{2}$ Assistant Professor, Department of Pulmonary Medicine, MGM Medical College, Indore. \\ 3 Professor and HOD, Department of Pulmonary Medicine, MGM Medical College, Indore. \\ ${ }^{4}$ Resident Medical Officer, Department of Pulmonary Medicine, MGM Medical College, Indore. \\ ${ }^{5}$ Assistant Professor, Department of Pulmonary Medicine, MGM Medical College, Indore.
}

ABSTRACT
BACKGROUND
In the present scenario, drug resistance is a huge obstacle in managing TB, as it is not only drug resis
also has huge financial and social burden.
Objectives of the study are-
1. To study the epidemiological pattern of pulmonary MDR-TB in central part of Madhya Pradesh.
2. To assess the risk factors for pulmonary MDR-TB.

\section{MATERIALS AND METHODS}

226 MDR-TB patients (with in-vitro resistance to rifampicin and isoniazid via line probe assay) presented to MY Hospital, Indore, were analysed over a period of one year of August 2015 to August 2016. This is a retrospective descriptive study. Analysis was done to know the epidemiological profile and assessment of risk factor for MDR-TB.

\section{RESULTS}

63.3\% patients were from age group 21 - 40 years. 61.9\% patients were male and 38.1\% were female. In terms of socio-demographic profile, grand total of $72.2 \%$ (urban slums $49.6 \%$, rural $22.6 \%$ ) belonged to underdeveloped area, whereas rest belonged to urban areas. 5.8\% (13) of total patients have positive family history, 10\% (22) were HIV positive, 10.6\% (24) were primary MDR patients, $15 \%$ (34) were treatment failure, 59.3\% (134) treatment interrupted and 61.9\% patients have mean body index between $10-15$ $\mathrm{kg} / \mathrm{m}^{2}$ (p value 0.163 ).

\section{CONCLUSION}

As young males are most commonly affected with MDR Tuberculosis, greater emphasis should be given on screening and treatment of young males. High percentages of patients were found to have low BMI. Awareness regarding proper nutrition and proper dietary supplements should be ensured since early adulthood. Health education and awareness program should be conducted in rural area and urban slums, as they form main source for the drug resistance TB. The bulk of patients are from treatment interrupted group, so strict compliance monitoring of all the patients on anti-tubercular treatment should be ensured. History of contact with MDR and PLHA are also independent risk factor for MDR-TB.

\section{KEYWORDS}

Tuberculosis, MDR, LPA.

HOW TO CITE THIS ARTICLE: Avashia S, Bansal D, Bhargava S, et al. A study of epidemiological pattern of multidrug resistant pulmonary tuberculosis patients presenting to a tertiary care centre in Central India. J. Evolution Med. Dent. Sci. 2018;7(08):962964, DOI: $10.14260 /$ jemds/2018/220

\section{BACKGROUND}

MDR-TB is caused by strains of mycobacterium tuberculosis, resistant to both rifampicin and isoniazid with or without resistance to other drugs. ${ }^{1}$ In present scenario drug resistant TB is a huge obstacle in managing tuberculosis, as it is not only difficult to treat but also has huge financial and social burden. In 2015, there were an estimated 480,000 new cases of multidrug-resistant TB (MDR-TB) and an additional 100,000 people with rifampicin-resistant TB (RR-TB) who

'Financial or Other Competing Interest': None.

Submission 12-12-2017, Peer Review 01-02-2018,

Acceptance 08-02-2018, Published 19-02-2018.

Corresponding Author:

Dr. Deepak Bansal,

\#11/2, Murai Mohalla,

Sanyogitagani, Indore-452001,

Madhya Pradesh.

E-mail: drbansaldeepak@gmail.com

DOI: $10.14260 /$ jemds $/ 2018 / 220$

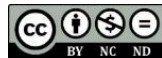

were also newly eligible for MDR-TB treatment. ${ }^{2}$ Drug resistance surveillance data show that $3.9 \%$ of new and $21 \%$ of previously treated TB cases was estimated to have rifampicin or multidrug-resistant tuberculosis (MDR/RR-TB) in 2015. As in 2014, MDR-TB accounts for 3.3\% of new TB cases. ${ }^{2}$ In India total 130,000 patients developed MDR-TB with incidence rate of $9.9 / 100,000 .^{2}$ With primary MDR, rate of $2.5 \%$ and $16 \%$ retreatment case. In India prevalence of MDR is $2 \%$ - 3\% among new cases and $12 \%-17 \%$ among re-infectious cases. ${ }^{3}$ Management of MDR-TB is expensive, prolonged and associated with various adverse effects with only 52\% treatment success rate for patients who were started treatment in 2013.2 Due to this prolonged course, drug resistance tuberculosis is associated with higher chance of transmission to contacts and health care providers. The root problem for the development of drug resistance is improper use of first line anti-tubercular drugs like inadequate dose, wrong regime, inadequate follow-up and poor counselling for adherence to treatment. 
Objectives of the Study

1. To study the epidemiological pattern of pulmonary MDRTB in central part of Madhya Pradesh.

2. To assess the risk factors for pulmonary MDR-TB.

\section{MATERIALS AND METHODS}

The study was conducted in Department of Respiratory Medicine, MGM Medical College and MY Hospital, Indore during period of one year from August 2015 to August 2016. It is a retrospective descriptive study including only 226 LPA proven pulmonary MDR tuberculosis cases presented to respiratory medicine outpatient department. The detailed history including socio-demographic profile was obtained from patients, relatives, medical records and DOTS provider.

\section{The Analysis was done to know Epidemiology Profile and to assess Various Risk Factors-}

\section{Inclusion Criteria}

Patient must be a known case of drug resistance pulmonary TB.

\section{Exclusion Criteria}

Concomitant extrapulmonary tuberculosis.

\section{RESULTS}

63.3\% patients were from age group 21 - 40 years (Table 1). $61.9 \%$ patients were male and $38.1 \%$ female. In terms of sociodemographic profile, grand total of $72.2 \%$ (urban slums $49.6 \%$, rural $22.6 \%$ ) belongs to underdeveloped area, whereas rest belonged to urban areas. 5.8\% (13) of total patients have positive family history, $10 \%$ (22) were HIV positive. $10.6 \%$ (24) were primary MDR patients, $15 \%$ (34) were treatment failure and 59.3\% (134) were treatment interrupted (Table 2). As shown in Table 3, 61.9\% patients have mean body index between $10-15 \mathrm{~kg} / \mathrm{m}^{2}$ ( $\mathrm{p}$ value 0.163 ).

\begin{tabular}{|c|c|c|}
\hline Age & Frequency & Percent \\
\hline $0-21$ & 27 & $11.9 \%$ \\
\hline $21-40$ & 143 & $63.3 \%$ \\
\hline $41-60$ & 47 & $20.8 \%$ \\
\hline$>60$ & 09 & $4 \%$ \\
\hline Total & $\mathbf{2 2 6}$ & $\mathbf{1 0 0}$ \\
\hline \multicolumn{2}{|c|}{ Table 1. Showing Age-Wise Distribution } \\
\hline
\end{tabular}

\begin{tabular}{|c|c|c|}
\hline Diagnosis & Frequency & Percent \\
\hline Relapse & 34 & 15 \\
\hline Failure & 34 & 15 \\
\hline $\begin{array}{c}\text { Treatment } \\
\text { Interrupted }\end{array}$ & 134 & 59.2 \\
\hline Primary Contact & 24 & 10.6 \\
\hline Total & $\mathbf{2 2 6}$ & $\mathbf{2 2 6}$ \\
\hline \multicolumn{2}{|r|}{ Table 2. Diagnosis Wise Distributions } \\
\hline
\end{tabular}

\begin{tabular}{|c|c|c|c|c|}
\hline BMI & $\mathbf{1 0 - 1 5}$ & $\mathbf{1 6 - 2 0}$ & $\mathbf{2 1 - 2 5}$ & $\mathbf{2 5}$ \\
\hline Age & 132 & 64 & 14 & 12 \\
\hline \multicolumn{5}{|c|}{ Table 3. BMI Wise Distributions } \\
\hline
\end{tabular}

\section{DISCUSSION}

In our study, it was found that young male population (21-40 years) is most commonly affected with MDR-TB, which is similar to study conducted by Mishra et al with $96.10 \%$ belonging to age less than 49 years, males $60.8 \%$ and Kapadia et al with mean age of presentation of $31+/-2$ and male predominance of $64.22 \% .4,5$ Low BMI ( $p$ value 0.163 ) is significantly associated with higher occurrence of drug resistance TB, which is similar to study conducted by Kumar et al ${ }^{6}$ with $68.6 \%$ found to be undernourished with a mean BMI of $17.33+1.99 \mathrm{~kg} / \mathrm{m}^{2} .1 .2$ million people living with HIV worldwide fell ill with TB in 2015.2 MDR-HIV co-infection rate is $9.6 \%$ which in comparison to Deivanayagam et al $(4.42 \%)^{7}$ is on higher side. Increased incidence can be attributed to various predisposing factors like poor immunity, higher chance of exposure due to more hospital visit and hospitalisation for other ailments, poor adherence to ATT and ART treatment and incomplete absorption of drug. ${ }^{8}$ In comparison to WHO 2015 - 16 data (3.4\%) and study conducted by K Sharma et $\mathrm{al}^{9}(1.1 \%)$, our study revealed higher percentage of primary MDR (10.6\%) which may be due to increased number of index MDR case leading to higher primary contacts. Close contacts of drug resistant TB when developed active TB mostly have resistant TB. ${ }^{10}$ Odds of drug resistant TB is $4-7$ times higher in previously treated compared to persons with no history of previous treatment. ${ }^{11}$ Our study also revealed $89.2 \%$ having previous treatment history. Due to significant relationship between previous ATT history and possibility of MDR, all such patients should be subjected to MDR workup. ${ }^{12}$

\section{CONCLUSION}

Our study concludes that young males are most commonly affected with MDR tuberculosis. Greater emphasis should be given on screening and treatment of young males, as they form the economic base of the family. Proper nutritional support is the need of the hour and high percentage of patients were found to have low BMI. Awareness regarding proper nutrition and proper dietary supplements should be ensured since early adulthood, as they form bulk of patients. Health education and awareness program should be conducted in rural area and urban slums, as they form main source for the Drug resistance TB. The bulk of patients are from Treatment interrupted group, so strict compliance monitoring of all the patients on anti-tubercular treatment should be ensured. We also conclude that MDR Tuberculosis as HIV MDR-TB co-infection was found on the higher side in our study.

\section{ACKNOWLEDGEMENTS}

We sincerely acknowledge the technical support and guidance of Dr. Atul Kharate (State Tuberculosis Officer, MP), Dr. Vijay Chhajlani (District Tuberculosis Officer, Indore) and Dr. VK Agrawal (Superintendent, MRTB Hospital, Indore). It would not have been possible to complete the study without their unending help.

\section{REFERENCES}

[1] Prasad R. Drug resistance and multidrug resistance tuberculosis. In: Clinical tuberculosis diagnosis and treatment. $1^{\text {st }}$ edn. New Delhi: Jaypee Brothers Medical Publisher 2015:312-3.

[2] WHO MDR TB Factsheet (PDF) 2016. http://www.who.int/tb/challenges/mdr/mdr_tb_facts heet.pdf.

[3] Sachdeva KS. Overview of drug-resistant TB in India and National Scale up of MDR TB Diagnosis and 
Treatment. Speaker presentation at the Institute of Medicine Workshop on Facing the Reality of DrugResistant Tuberculosis in India: Challenges and Potential Solutions. New Delhi, April 18, 2011.

[4] Mishra JK, Sehgal D, Anupurba S, et al. Pattern of drug resistance in tuberculosis patients attending tertiary care hospital, Varanasi. Indian J Prev Soc Med 2009;40(1-2):101-5.

[5] Kapadia VK, Tripathi SB. Adverse drug reactions and outcome analysis of MDR TB patients on DOTS plus regimen. Ntl J Community Med 2015;7(1):5-9.

[6] Amit K, Rakesh K, Kandpal SD, et al. Nutritional status in multi-drug resistance-pulmonary tuberculosis patients. Indian Journal of Community Health 2014;26 Suppl 2:204-8.

[7] Deivanayagam CN, Rajasekaran S, Venkatesan R, et al. Prevalence of acquired MDR-TB and HIV co-infection. Indian J Chest Dis Allied Sci 2002;44(4):237-42.
[8] Sharma KS, Mohan A. Multidrug-resistant tuberculosis. Indian J Med Res 2004;120:354-76.

[9] Sharma SK, Kaushik G, Jha B, et al. Prevalence of multidrug-resistant tuberculosis among newly diagnosed cases of sputum-positive pulmonary tuberculosis. Indian J Med Res 2011;133(3):308-11.

[10] Prasad R. Multi drug resistant tuberculosis contacts: management. In: Clinical tuberculosis diagnosis and treatment. $1^{\text {st }}$ edn. New Delhi: Jaypee Brothers Medical Publisher 2015:362-6.

[11] Prasad R. Drug resistant and multidrug resistant tuberculosis. In: Clinical tuberculosis diagnosis and treatment. $1^{\text {st }}$ edn. New Delhi: Jaypee Brothers Medical Publisher 2015:296-310.

[12] Kandi S, Prasad SV, Reddy PNS, et al. Prevalence of multidrug resistance among retreatment pulmonary tuberculosis cases in a tertiary care hospital, Hyderabad, India. Lung India 2003;30(4):277-9. 